\title{
DEVELOPMENT OF EARLY WARNING MODELING SYSTEM FOR SUDDEN CHEMICAL SPILL IN PLAIN RIVER NETWORK
}

\author{
Hai-Long Yin \\ Key Laboratory of Yangtze Aquatic Environment, Ministry of Education, Tongji University, Shanghai, P.R.C. \\ Zu-Xin Xu \\ State Key Laboratory of Pollution Control and Resource Reuse, Tongji University, Shanghai, P.R.C., xzx@stcsm.gov.cn \\ Chen Wang \\ State Key Laboratory of Pollution Control and Resource Reuse, Tongji University, Shanghai, P.R.C. \\ Da Yu \\ Key Laboratory of Yangtze Aquatic Environment, Ministry of Education, Tongji University, Shanghai, P.R.C.
}

Follow this and additional works at: https://jmstt.ntou.edu.tw/journal

Part of the Engineering Commons

\section{Recommended Citation}

Yin, Hai-Long; Xu, Zu-Xin; Wang, Chen; and Yu, Da (2011) "DEVELOPMENT OF EARLY WARNING MODELING SYSTEM FOR SUDDEN CHEMICAL SPILL IN PLAIN RIVER NETWORK," Journal of Marine Science and Technology. Vol. 19: Iss. 6, Article 7. DOI: $10.51400 / 2709-6998.2205$

Available at: https://jmstt.ntou.edu.tw/journal/vol19/iss6/7

This Research Article is brought to you for free and open access by Journal of Marine Science and Technology. It has been accepted for inclusion in Journal of Marine Science and Technology by an authorized editor of Journal of Marine Science and Technology. 


\section{DEVELOPMENT OF EARLY WARNING MODELING SYSTEM FOR SUDDEN CHEMICAL SPILL IN PLAIN RIVER NETWORK}

\section{Acknowledgements}

We would like to thank Ministry of Science and Technology of the P.R.C for the funding of this research project (No.2007AA06A401). We also would like to acknowledge the finance supported by the state's Major Science and Technology Program for Water Pollution Control and Treatment (No.2009ZX07316-005), and the foundation of State Key Laboratory of Pollution Control and Resource Reuse (Tongji University) (No.PCRRY11009). 


\title{
DEVELOPMENT OF EARLY WARNING MODELING SYSTEM FOR SUDDEN CHEMICAL SPILL IN PLAIN RIVER NETWORK
}

\author{
Hai-Long Yin*, Zu-Xin $\mathrm{Xu}^{* *}$, Chen Wang**, and Da Yu*
}

Key words: hydrodynamic model, water quality model, oil spill, hydrophobic model, hydrophilic model, river network.

\begin{abstract}
An early warning modeling system for assessing potential river water quality threat from sudden chemical discharge incidents was developed, based on a hydrodynamic model for tidal plain river network equipped with sluice gates and water quality models. For the hydrodynamic model, the mode to simulate river flow under artificial irreversible gate operation was presented, so that the flow related to gate control with tidal occurrence could be simulated, which was calibrated by the measured data. For the water quality models, three kinds of models including oil spill model, hydrophobic model and hydrophilic model were developed based on chemical properties. With China's Shanghai river network waters as the domain, oil spill scenario and hexachlorobenzene (HCB) spill scenario representing hydrophobic chemical were simulated based on the verified model parameters, and showed the application of the developed early warning modeling system.
\end{abstract}

\section{INTRODUCTION}

To tackle the sudden water pollution incident effectively, the early warning modeling is of increasing concern so as to guide environmental engineers and planners in designing and carrying out effective clean-up operations. Among these models, many focus on the fate and surface movement of oil spill. Several advanced oil-spill modeling systems have been developed such as OILMAP [13-15], OSIS [7, 9] and OSCAR [1, 10-12]. Some mathematical models with analytical solutions have also been developed to predict advection and diffusion of oil concentration in water [18]. Unlike more common surface spills, the Deepwater Horizontal incident happened in June

Paper submitted 12/12/09; revised 04/21/11, 10/08/11; accepted 11/09/11. Author for correspondence: Zu-XinXu (e-mail: xzx@stcsm.gov.cn).

*Key Laboratory of Yangtze Aquatic Environment, Ministry of Education, Tongji University, Shanghai, P.R.C.

**State Key Laboratory of Pollution Control and Resource Reuse, Tongji University, Shanghai, P.R.C.
2010, was the first deepwater spill in which chemical dispersants were directly added to the oil pouring out of the wellhead. So, a new computational model to predict the environmental fate and impact of the marine oil and chemical dispersant was justly developed [16]. However, for the deposition and adsorption of oil by sediment, only a few researches were found, and many other models didn't consider these processes $[2,3,6]$. For the other chemicals spill into rivers, deposition and adsorption related to sediment is also the process to be discussed. In view of the limited understanding of the chemicals process, the simulations for chemicals spill has room for improvement.

Apart from the understanding of chemical spill process in aquatic environment, how to establish the modeling system for assessing chemicals fate with water flow in the cross-linking river network is also the focus. After all, the current early warning modeling system are usually applicable to the single rivers or open waters, but less efficient in the river network, especially the water system equipped with sluice gates to control water flowing, which decides the chemicals spreading domain.

This paper reports newly developed chemical spill models for simulating the movement of chemicals in plain river network, based on a hydrodynamic model for the river network equipped with sluice gates and a water quality model. Using Shanghai waters as a test bed, the numerical simulations were carried out and the results are verified with observed and experimental data.

\section{HYDRODYNAMIC MODEL FOR THE RIVER NETWORK}

\section{Model Governing Equation}

Considering lateral and vertical scale is much smaller than the longitudinal scale in the river network, generally the governing equation of the hydrodynamic model is based on Saint-Venant Eq.:

$$
\begin{gathered}
B_{t} \frac{\partial \zeta}{\partial t}+\frac{\partial Q}{\partial x}=q \\
\frac{\partial Q}{\partial t}+\frac{\partial}{\partial x}\left(\alpha \frac{Q^{2}}{A}\right)+g A \frac{\partial \zeta}{\partial x}+g \frac{n^{2} Q^{2}}{A h^{4 / 3}}=0
\end{gathered}
$$




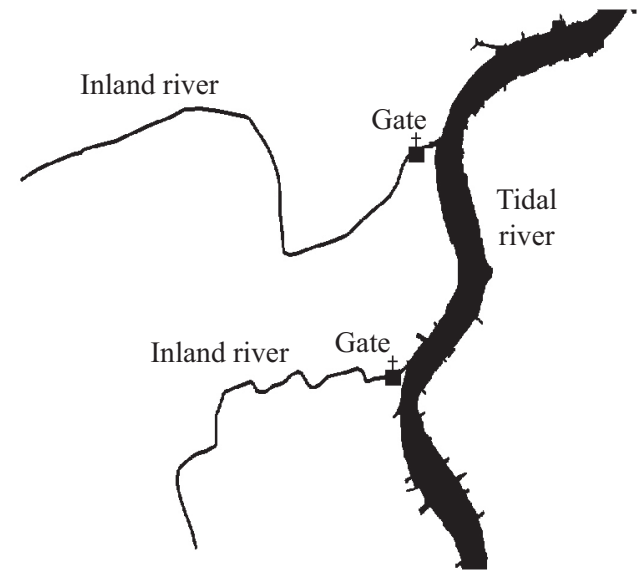

Fig. 1. Schematic map of gates control in the tidal river network.

where $x$ and $t$ are longitudinal distance and time respectively; $A$ is cross sectional area; $Q$ is discharge; $\zeta$ is water level; $h$ is water depth; $q$ is lateral inflow; $g$ is acceleration due to gravity; $n$ is bottom roughness coefficient.

\section{Mode to Control Sluice Gates}

Plain river network is usually formed in the coastal region. To prevent flooding from tidal propagation, many sluice gates had been installed in the tidal rivers. In the past, under most circumstances, the sluice gates were closed, as a result the river flowing among the rivers were severed, causing stagnant flow. To augment river flowing with the purpose of improving water quality, dynamic gates operation were implemented, relating to gates control mode with tidal occurrence in the model.

Generally, gate operation is irreversible so as to achieve a unidirectional flow. As shown in Fig. 1, gate's outside river is a natural tidal river, and gate operation is decided by the water elevation between the inside and outside river. One scenario is that, only when water elevation inside river is high than that outside river during low tide, gate is opened to achieve a west-east flow, and gate is closed at other time. The other scenario is that, only when water elevation inside river is lower than that outside river during high tide, gate is opened to achieve an east-west flow.

When gate is opened, the discharge across sluice gate is usually computed according to the following equation:

$$
Q_{g}=C_{s} B_{g} \zeta_{s} \sqrt{2 g\left(\zeta_{0}-\zeta_{s}\right)}
$$

where $Q_{g}$ is discharge across sluice gates; $C_{s}$ is submerged orifice flowing coefficient; $B_{g}$ is lateral gate orifice width; $\zeta_{0}$ is gate upstream water depth above gate elevation, that is, $\zeta_{0}=$ $\zeta_{u}-\zeta_{g}, \zeta_{u}$ is gate upstream water elevation, $\zeta_{g}$ is gate bottom elevation; $\zeta_{s}$ is gate downstream water depth above gate elevation, that is, $\zeta_{s}=\zeta_{d}-\zeta_{g}, \zeta_{d}$ is gate downstream water elevation.

When gate is closed, the discharge across the sluice gate is zero.

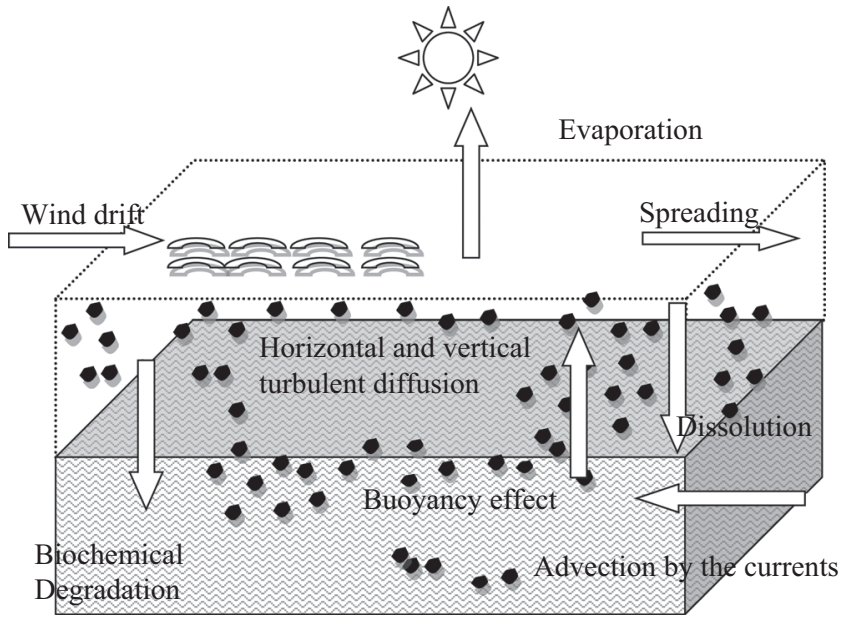

Fig. 2. Fate and transport of oil in water.

\section{River Junction}

Usually it is mandated that mass is conserved, and all water levels match at the junction, that is,

$$
\zeta_{1}=\zeta_{2}=\cdots=\zeta_{n}
$$

where $\zeta_{1}, \zeta_{2}, \zeta_{n}$ are water level at junction point $1,2, n$ respectively.

\section{CHEMICAL SPILL MODEL}

\section{Oil Spill Model}

During the early stages of an oil spill, the fate and transport of spilled oil is governed mainly by spreading due to gravity, advection and horizontal turbulent diffusion due to current and wind, evaporation and volatilization due to weathering processes, and vertical dispersion due to breaking waves and upper layer turbulence. Under the actions of breaking wave and upper layer turbulence, the thinner oil slick may break up into small particles, which advect, diffuse and degrade in water. The fate and transport process is explained as Fig. 2.

An oil spill model is further developed to simulate the particle concentration distribution by using the mass transport based on the hydrodynamic model. The model can be described by

$$
\frac{\partial A C}{\partial t}+\frac{\partial Q C}{\partial x}=\frac{\partial}{\partial x}\left(A D_{x} \frac{\partial C}{\partial x}\right)+\frac{w}{h} A C-k_{b} A C
$$

where $C$ is particle concentration in water; $D_{x}$ is mixing coefficient in the longitudinal direction; $w$ is settling velocity of oil particles, usually $w<0$ due to less dense than water; $k_{b}$ is chemical and biological degradation under water surface.

\section{Hydrophobic Chemicals Model}

Much of the hydrophobic chemical is sorbed to particulate 


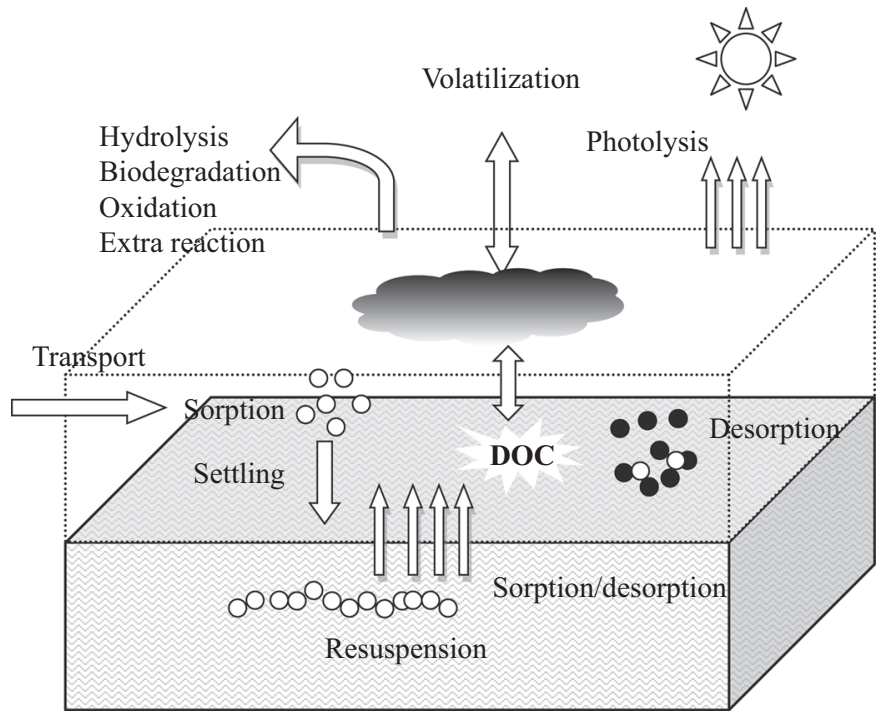

Fig. 3. Fate and transport of hydrophobic chemicals in water.

matter and is transported with it. This particulate matter, along with the sorbed chemical, usually settles onto the bottom of river and forms deposits of contaminated sediments.

In general, the fate of hydrophobic chemicals in the river is determined by partitioning to water and particulate matter, and by transport, as shown in Fig. 3.

The mass conservation equation for the chemical dissolved in water is

$$
\begin{aligned}
\frac{\partial A C_{d}}{\partial t}+\frac{\partial Q C_{d}}{\partial x}= & \frac{\partial}{\partial x}\left(A D_{x} \frac{\partial C_{d}}{\partial x}\right)-k_{s} k_{p} \theta A C_{d} \\
& +k_{d} k_{p} \theta A C_{d}-k_{b} A C_{d}
\end{aligned}
$$

where $C_{d}$ is the dissolved chemical concentration in water; $k_{s}$ is sorption rate; $k_{d}$ is desorption rate; $k_{p}$ is partition coefficient between suspended sediments and water; $\theta$ is suspended sediments concentration in water; $k_{b}$ is chemical and biological degradation including the process of volatilization, hydrolysis, photolysis, etc.

The mass conservation equation for the chemical sorbed to suspended sediments is

$$
\begin{aligned}
& \frac{\partial A C_{s}}{\partial t}+\frac{\partial Q C_{s}}{\partial x}+P_{w} \frac{w_{s}}{h} A C_{s}-P_{r} \frac{E}{h} A C_{s} \\
& =\frac{\partial}{\partial x}\left(A D_{x} \frac{\partial C_{s}}{\partial x}\right)+k_{s} k_{p} \theta A C_{d}-k_{d} k_{p} \theta A C_{d}-k_{b} A C_{s}
\end{aligned}
$$

where $C_{s}$ is the sorbed chemical concentration in water; $w_{s}$ is settling velocity; $E$ is re-suspension rate; $P_{w}$ is probability for sedimentation, $P_{w}=\max \left(0,1-\frac{T}{T_{c r}^{\text {sed }}}\right), T_{c r}^{\text {sed }}$ is critical shear stress for sedimentation, $T$ is ambient shear stress; $P_{r}$ is

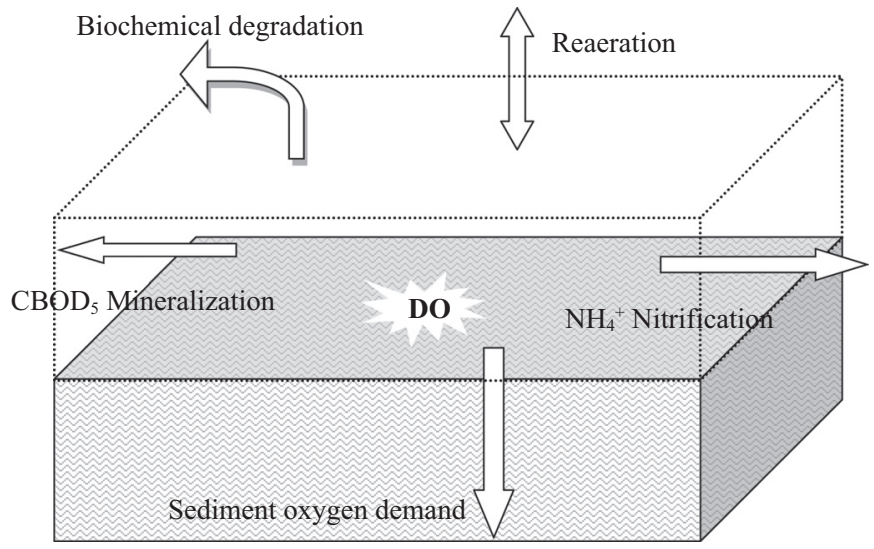

Fig. 4. Fate and transport of hydrophilic organic pollutants in water.

probability for re-suspension, $P_{r}=\max \left(0, \frac{T_{c r}^{r e s}}{T}-1\right), T_{c r}^{r e s}$ is critical shear stress for re-suspension.

\section{Hydrophilic Chemicals Model}

Fate and transport of hydrophilic chemicals in water is predominantly determined by advection, turbulent diffusion and bio-chemical degradation, which is described by

$$
\frac{\partial A C}{\partial t}+\frac{\partial Q C}{\partial x}=\frac{\partial}{\partial x}\left(A D_{x} \frac{\partial C}{\partial x}\right)-k_{b} A C
$$

where $k_{b}$ is boil-chemical degradation. The degradability of hydrophilic chemicals usually decreases as chemicals ages. From a more general level, considering the chemicals in waters include a variety of organic compounds, collective parameters such as chemical oxygen demand (COD), biochemical oxygen demand (BOD), total organic carbon (TOC), particulate organic carbon (POC) or dissolved organic carbon (DOC) are often used to estimate the quantity of these organic matter. A general dissolved oxygen (DO) model is illustrated as Fig. 4.

\section{RESULATS AND DISCUSSION}

\section{Study Area}

Study area is Shanghai river network, covering an area of $6000 \mathrm{~km}^{2}$. With Yangtze Estuary to the north, tidal waters propagate into the region via Wusongkou of Huangpu River, as far as Dianfeng (Fig. 5). So, the area is characterized as a tidal river network. Sluice gates were equipped in rivers to control river flowing according to tidal flowing regime in the Huangpu River.

Hydrodynamic model was calibrated with measured data in 2004 in the Huangpu River as well as its tributaries like Suzhou Creek. The calibrated parameter is river's bottom roughness coefficient, which is calibrated to be in the range of 0.02 0.03. As sown in Fig. 5, Huangpu River is the mainstream 


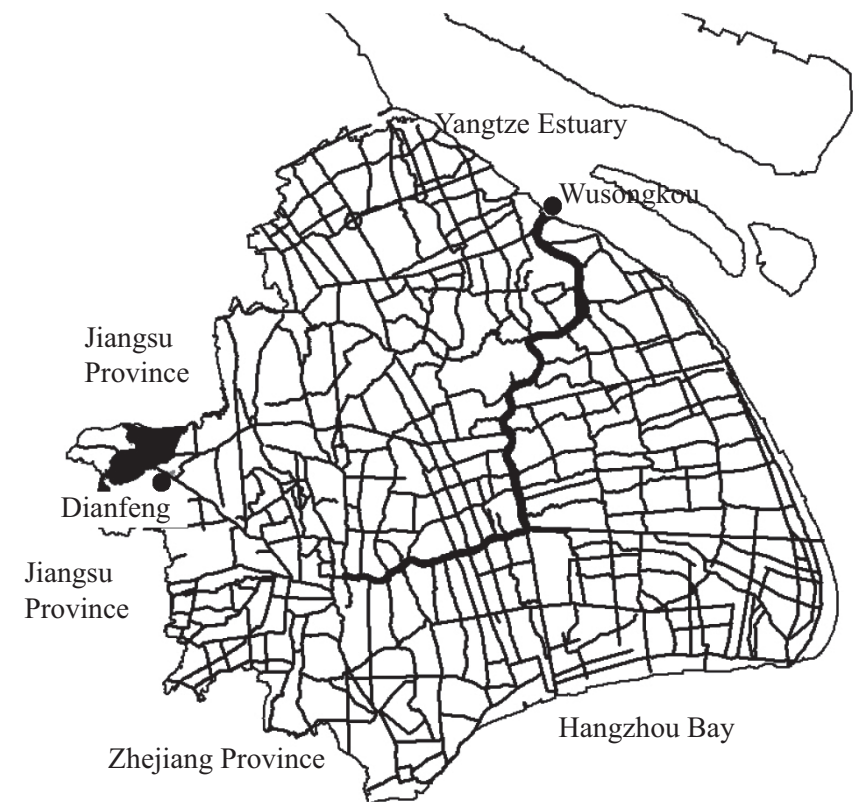

Fig. 5. Depiction of study area.

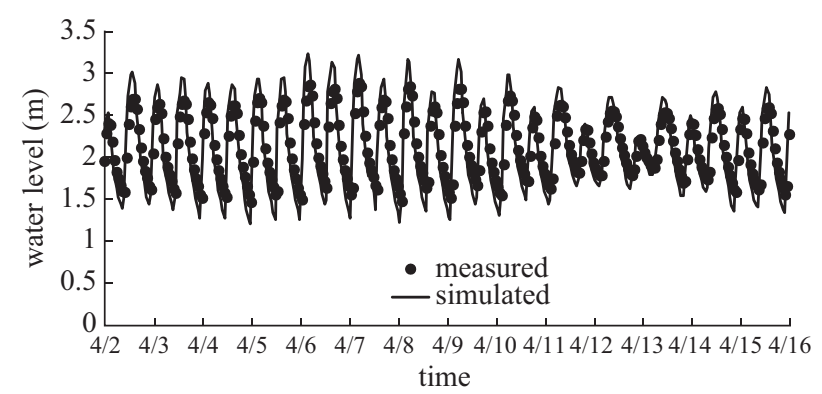

(a)

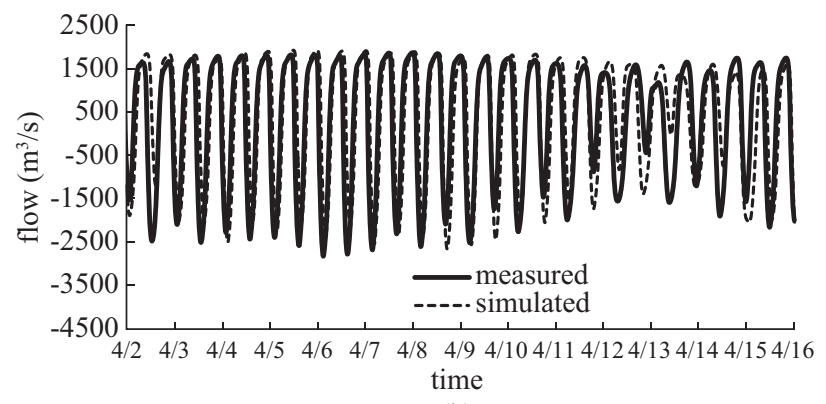

(b)

Fig. 6. Hydrodynamic model calibration at Huangpu River: (a) water elevation of Songpu bridge station and (b) water flowing of Songpu bridge station.

of this watershed, so calibration of flowing pattern of Huangpu River proves the total tidal flow into the area (Fig. 6). Suzhou Creek is Huangpu River's largest tributary, which is controlled by sluice gates equipped in the Huangpu River and other rivers (Fig. 7); so, calibration of flowing pattern of Suzhou Creek proves water flowing of this region under sluice gate control (Fig. 8).

In this study, potential chemical spills in Minhang District

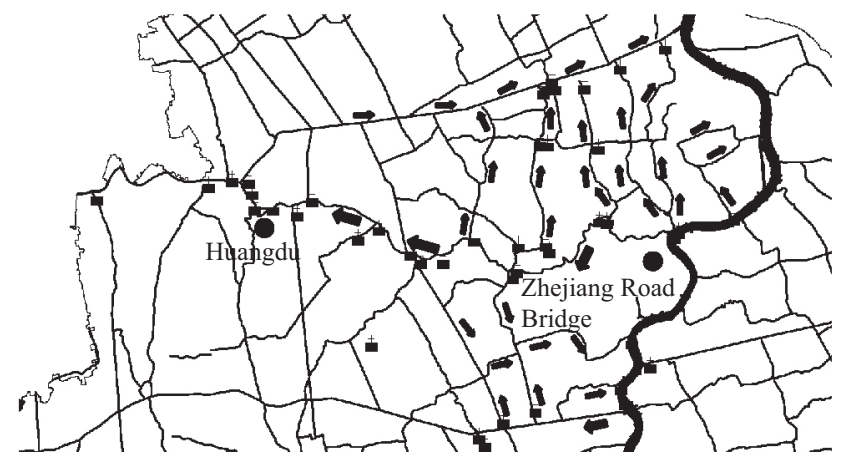

Fig. 7. Water flowing dispatch of Suzhou Creek based on sluice gates control.

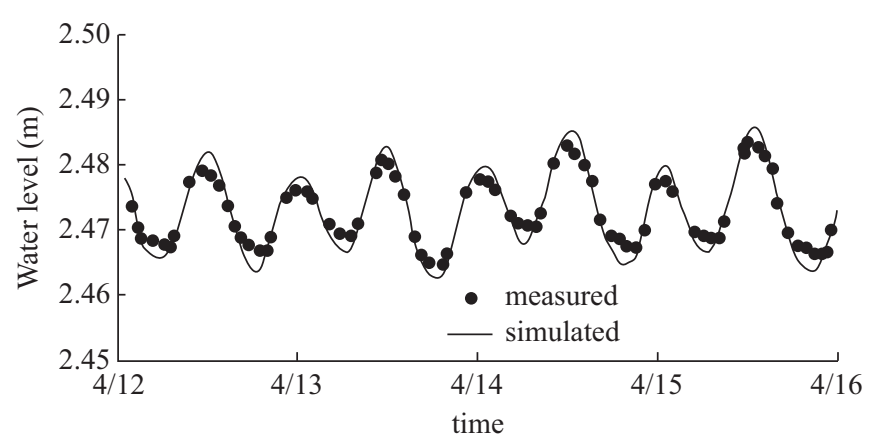

(a)

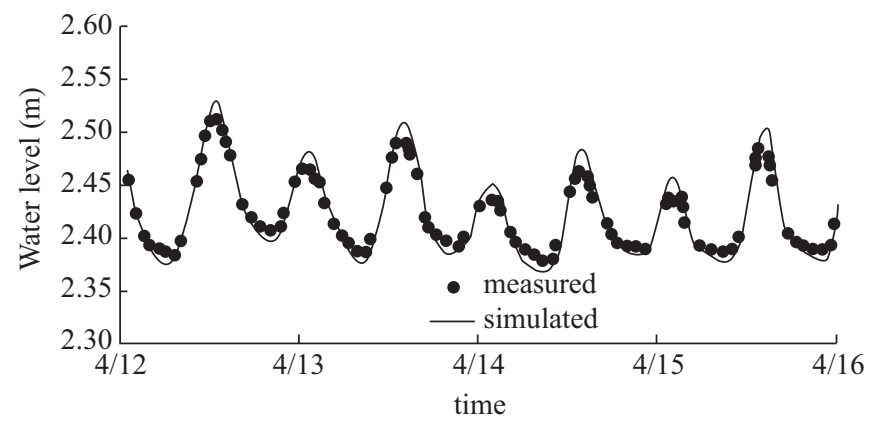

(b)

Fig. 8. Hydrodynamic model calibration at Suzhou Creek: (a) water elevation of Huangdu station and (b) water elevation of Zhejiang Road bridge station.

of Shanghai were assessed, based on the developed hydrodynamic model and chemical spill models. Minhang District is the region abundant in chemical enterprises and rivers, so chemical spill threat to the rivers is of increasing concern. Especially, rivers in this region were refined so as to include any of the potential chemical spills (Fig. 9).

\section{Oil Spill Scenario}

Oil and its refinery products are the most common potential risks in this area, which are usually generalized as the mixture of the components including alkane, cycloparaffins, mononuclear aromatics, naphthalenes, etc. The processes in the oil spill model are presented in Table 1 based on the parameters verification from a series of studies [4, 19]. 


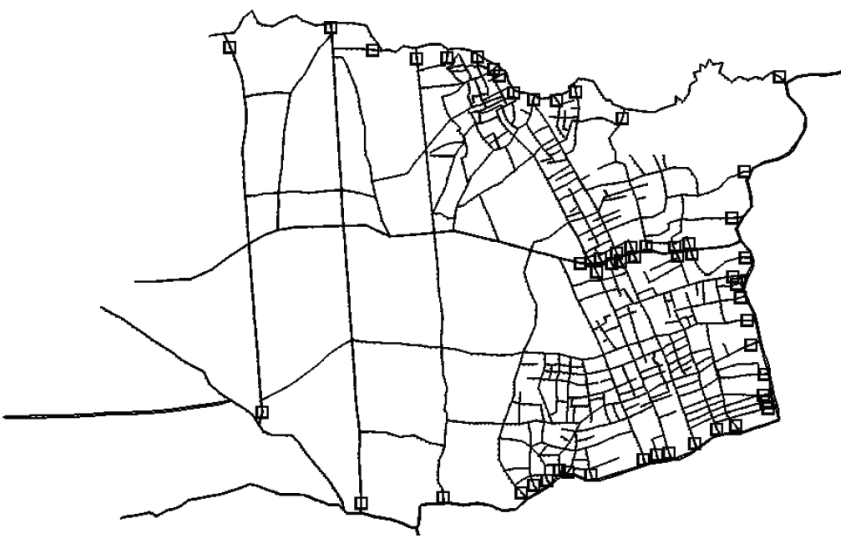

Fig. 9. Refined water courses in Minhang District of Shanghai.

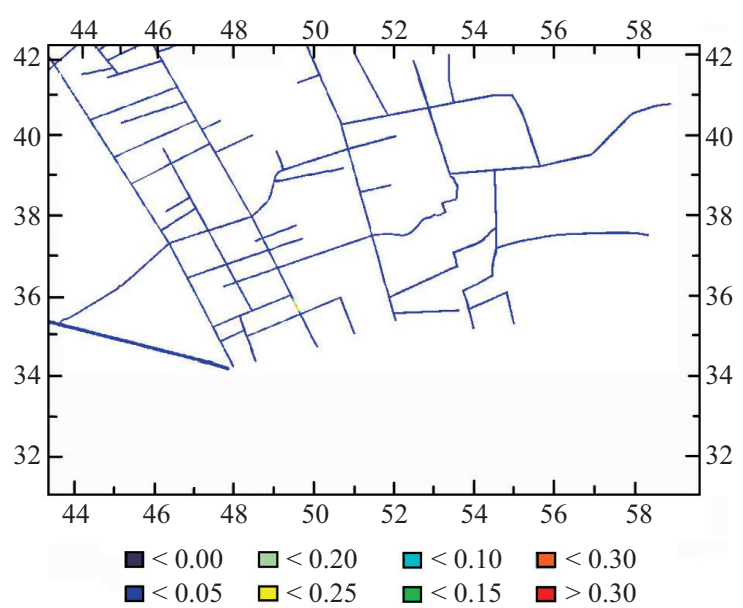

(a) $30 \mathrm{~min}$

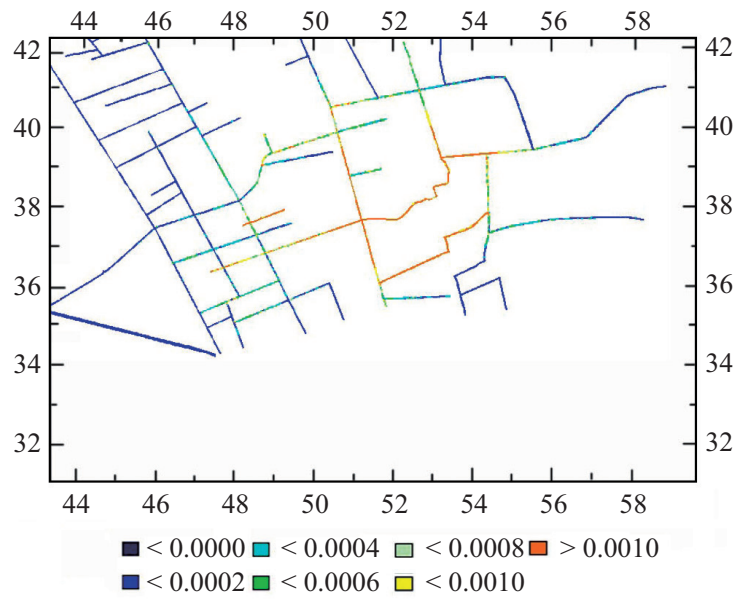

(c) $12 \mathrm{~h}$
Table 1. Oil parameters and some parameters in the oil spill model.

\begin{tabular}{|l|l|}
\hline Properties of Oil & Parameters \\
\hline Oil type & Crude oil \\
\hline Oil density & $850 \mathrm{~kg} / \mathrm{m}^{3}$ \\
\hline Oil kinematic viscosity & $50 \mathrm{cSt}$ \\
\hline Oil maximum water content & 1.0 \\
\hline Wind drag coefficient & 0.03 \\
\hline Horizontal diffusion coefficient & $5 \mathrm{~m}^{2} / \mathrm{s}$ \\
\hline Minimum thickness & $0.5 \mathrm{~mm}$ \\
\hline Evaporation rate & $0.4 \mathrm{~d}^{-1}$ \\
\hline Dispersion rate & Calculated \\
\hline Oil settling velocity & Calculated \\
\hline
\end{tabular}

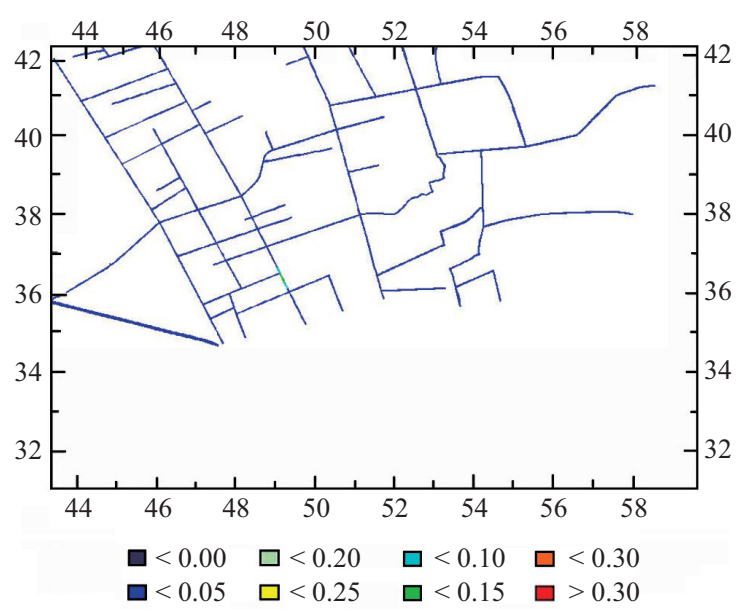

(b) $1 \mathrm{~h}$

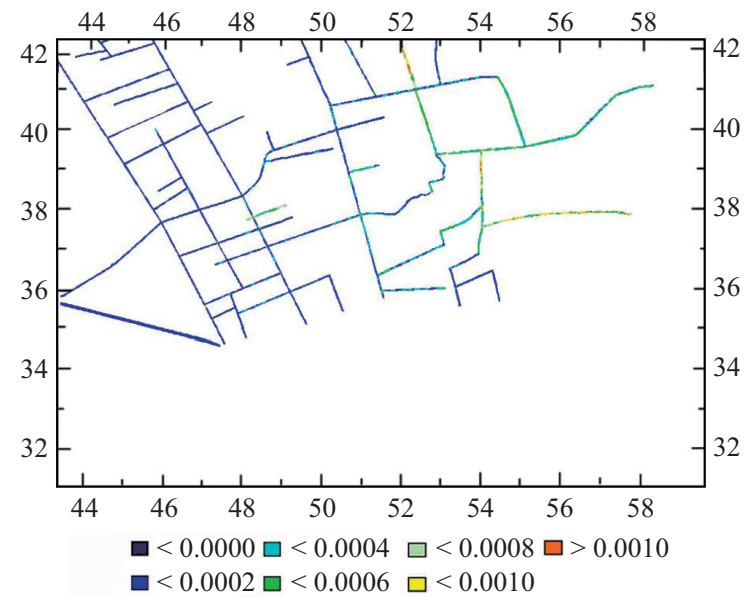

(d) $24 \mathrm{~h}$

Fig. 10. Oil movement and oil concentration on water surface of study domain.

Settling velocity of oil droplet is calculated based on Stokes Equation:

$$
w_{s}=\frac{1}{18} \frac{\rho_{o}-\rho_{w}}{\mu_{w}} g d^{2}
$$

Where $\rho_{0}$ is oil density; $\rho_{w}$ is water density; $\mu_{w}$ is water viscosity; $d$ is oil diameter, $d=100 \mu \mathrm{m}$. Based on Eq. (9), it is calculated that settling velocity of oil droplet is $-1.25 \times 10^{-4} \mathrm{~m} / \mathrm{s}$.

Dispersion rate of oil droplet is calculated based on the equation as follows: 


$$
\begin{gathered}
Q=\int_{d \min }^{d \max } Q(d) \Delta d \\
Q(d)=C^{\prime \prime \prime} D_{e}^{0.57} F_{w c} N_{0} d^{0.7} \\
D_{e}=0.000584 \rho_{w} U_{w}^{2} \\
F_{w c}=\frac{\max \left(0,0.032\left(U_{w}-5.0\right)\right)}{8.13 U_{w} / g}
\end{gathered}
$$

where $Q$ is dispersion rate; $Q(d)$ is dispersion rate of oil particles with particle sizes in an interval $\Delta d$ around $d ; N_{0}$ is normalisation constant distribution function; $d_{\min }$ is minimal oil droplet diameter; $d_{\max }$ is maximal oil droplet diameter; $C^{\prime \prime}$ is oil constant relating to oil kind; $D_{e}$ is wave energy dissipation per unit surface area; $F_{w c}$ is number of waves that break per unit surface area; $\rho_{w}$ is water density; $U_{w}$ is wind speed.

The following conditions were considered in the oil spill simulation:

Type of oil: 1 tons crude oil;

Simulation period: two days;

Wind: Southeast wind with the speed of $4.0 \mathrm{~m} / \mathrm{s}$;

Water flowing pattern: Based on the developed hydrodynamic model, the flowing field of the simulation area can be obtained;

Oil process: Based on the process described in Table 1.

Oil spreading and oil concentration on water surface is shown in Fig. 10. It can be seen that oil spreads with water flowing and wind, but oil concentration becomes smaller with time due to its strong evaporation. After 12 hours of sudden discharge, oil concentration on water surface is less than 0.001 $\mathrm{mg} / \mathrm{L}$, while oil spreading domain decreases gradually.

Oil dispersed in water can be excluded from consideration. The reason is that oil dispersion rate is insignificant, which is less than $10^{-5}$ in the simulation scenario.

\section{Hydrophobic Chemical Spill Scenario}

In this paper, potential HCB discharge was assessed. The parameters used in the model are presented in Table 2 based on the parameters verification from a series of studies $[5,8,17]$.

Volatilization rate is based on the double film theory, which can be defined as

$$
\frac{1}{k_{v}}=\frac{1}{k_{L}}+\frac{R T}{k_{g} k_{H}}
$$

where $k_{v}$ is volatilization rate; $k_{L}$ is transfer coefficient for the hydrophobic chemicals for the liquid film; $k_{g}$ is transfer coefficient for the hydrophobic chemicals for the gas film; $k_{H}$ is Henry's constant, $k_{H}=70 \mathrm{~Pa} \mathrm{~m} / \mathrm{mole} ; T$ is absolute water temperature $(K), R$ is gas constant.
Table 2. HCB properties and some parameters used in the hydrophobic chemical spill model.

\begin{tabular}{|l|l|}
\hline Properties of HCB & Parameters \\
\hline HCB density & $2440 \mathrm{~kg} / \mathrm{m}^{3}$ \\
\hline Horizontal diffusion coefficient & $5 \mathrm{~m}^{2} / \mathrm{s}$ \\
\hline Partition coefficient (Log form) & $6.41 \mathrm{~L} / \mathrm{kgC}$ \\
\hline Settling velocity & $2.0 \times 10^{-4} \mathrm{~m} / \mathrm{s}$ \\
\hline Re-suspension rate & $0.1 \mathrm{~g} / \mathrm{m}^{2} / \mathrm{s}$ \\
\hline Critical shear stress for sedimentation & $0.2 \mathrm{~N} / \mathrm{m}^{2}$ \\
\hline Critical shear stress for re-suspension & $0.3 \mathrm{~N} / \mathrm{m}^{2}$ \\
\hline Sediment concentration & $30 \mathrm{mg} / \mathrm{L}$ \\
\hline Adsorption rate & $0.42 \mathrm{~d}^{-1}$ \\
\hline Desorption rate & $0.10 \mathrm{~d}^{-1}$ \\
\hline Volatilization rate & Calculated \\
\hline
\end{tabular}

$k_{g}$ can be calculated as follows

$$
k_{g}=273.15 \times\left(U_{w}+U\right) \times \sqrt{\frac{18}{M_{w}}}
$$

$k_{L}$ can be calculated as follows for the wind speed greater than $1.9 \mathrm{~m} / \mathrm{s}$ and less than $5.0 \mathrm{~m} / \mathrm{s}$ :

$$
k_{L}=5.64 \times\left(\frac{U^{0.969}}{H^{0.673}}\right) \times \sqrt{\frac{32}{M_{w}}} \times e^{(0.526 \times(U-1.9))}
$$

where $H$ is water depth; $M_{w}$ is molecular weight; $U$ is water flowing velocity.

The following conditions were considered in the HCB spill simulation:

Quantity of HCB: 1 tons;

Simulation period: two days;

Water flowing pattern: Based on the developed hydrodynamic model, the flowing field of the simulation area can be obtained;

HCB process: Based on the process described in Table 2. $\mathrm{HCB}$ process is simulated as dissolved $\mathrm{HCB}$ and particulate $\mathrm{HCB}$ respectively.

Fate and transport of dissolved HCB and particulate HCB in the rivers is shown in Fig. 11 and Fig. 12. It can be seen that concentration of particulate $\mathrm{HCB}$ increases with time due to its larger partition coefficient on the order of $10^{6} \mathrm{~L} / \mathrm{kg}$. At the same time, the particulate matter, along with the sorbed HOC, also settles onto the bottom of an aquatic system and forms deposits of contaminants. Because of its biochemically refractory character in water, in the relatively long term, dissolved HCB concentration as well as particulate HCB concentration is larger than the oil concentration on the water surface under same discharge quantity for the simulation 


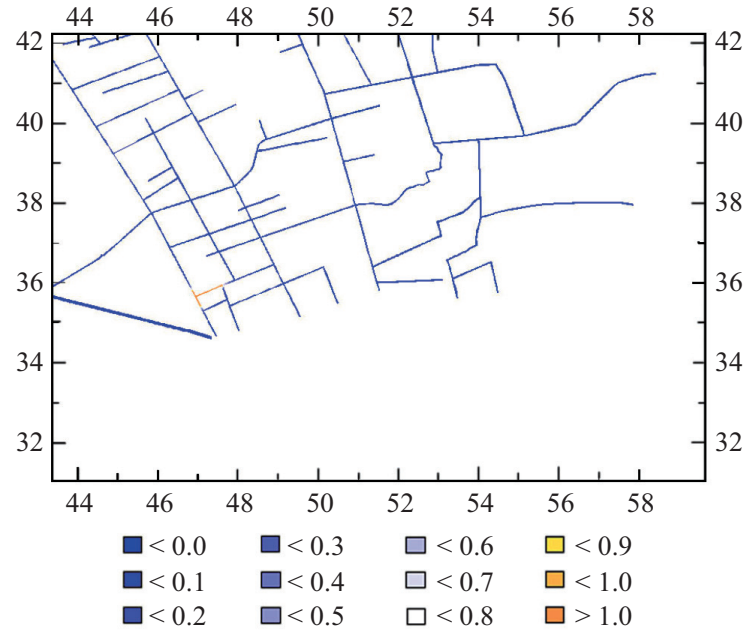

(a) $30 \mathrm{~min}$

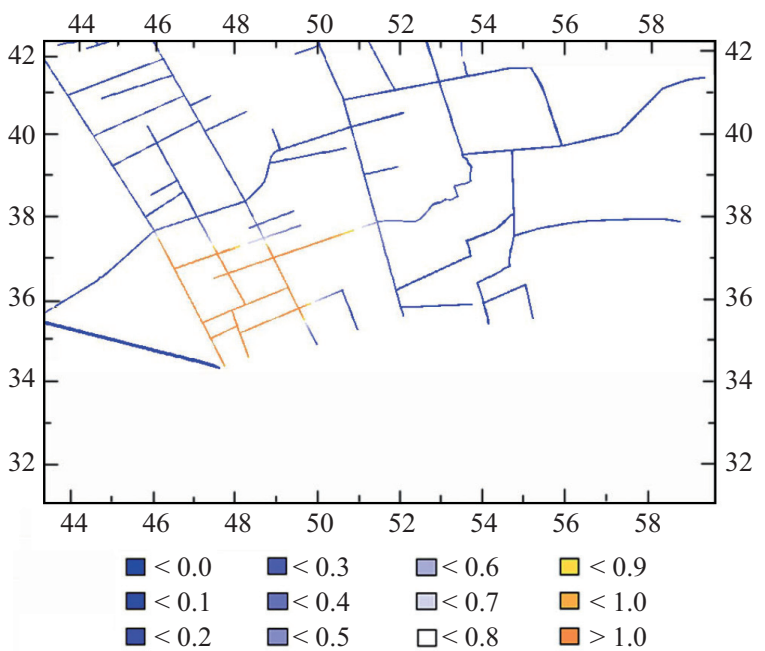

(c) $12 \mathrm{~h}$

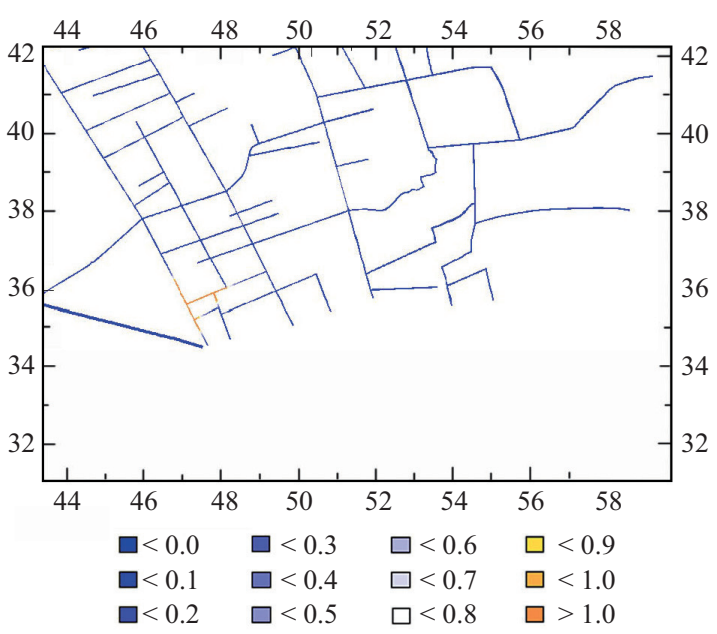

(b) $1 \mathrm{~h}$

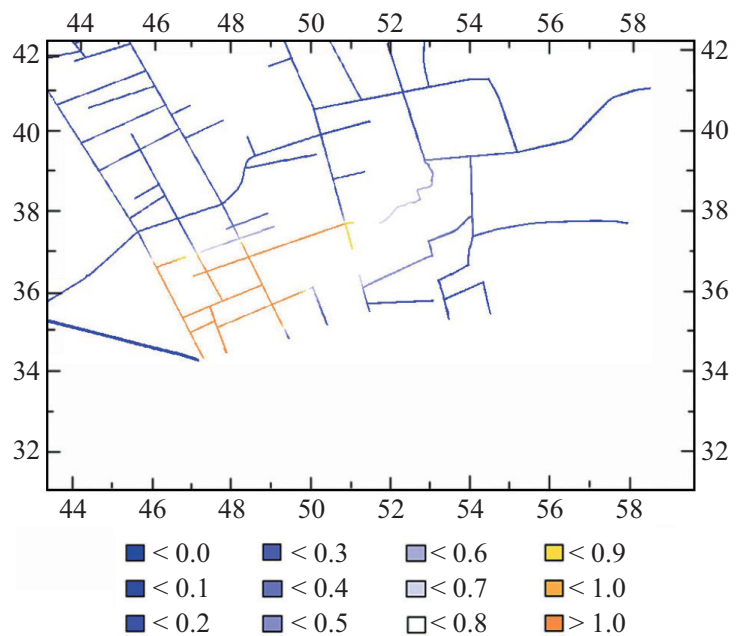

(d) $24 \mathrm{~h}$

Fig. 11. Fate and transport of dissolved HCB in the rivers of study domain.

scenarios. So, it is suggested that PCB transport in waters should be blocked as quickly as can after its discharge.

\section{CONCLUSION}

An early warning modeling system for tidal river network region has been developed to simulate the fate and transport of chemicals in rivers from a potential sudden chemical discharge.

To assess chemicals transport in rivers, a hydrodynamic model was firstly developed to simulate river flowing field under rivers junction and artificial sluice gates control. Compared with the observed data of Huangpu River and Suzhou Creek, the numerical results of the hydrodynamic model show good conformity.

Further, according to chemical properties, three kinds of water quality models including oil spill model, hydrophobic chemical model, and hydrophilic chemical model were developed. Oil spill model is capable of predicting the hori- zontal movement of surface oil slick and oil particle concentration distribution in water body. Hydrophobic chemical model is capable of predicting fate of chemicals in rivers dependant on the adsorption to sediments with sedimentation and re-suspension, as well as chemical and biological process. Hydrophilic chemical model is capable of predicting fate of organic compounds in rivers relating to chemical and biological degradation. The hydrodynamic model and three kinds of water quality models form an integrated modeling system to assess potential river water quality threat from sudden chemical discharge accidents in plain river network region.

Using Shanghai waters as a study area, two chemical spill scenarios including potential oil spill and HCB spill as hydrophobic chemical were simulated to display the application of early warning modeling system, based on the calibration of model parameters. The authors will collect more field measurements of sudden chemical discharge accident to refine the developed modeling system. 


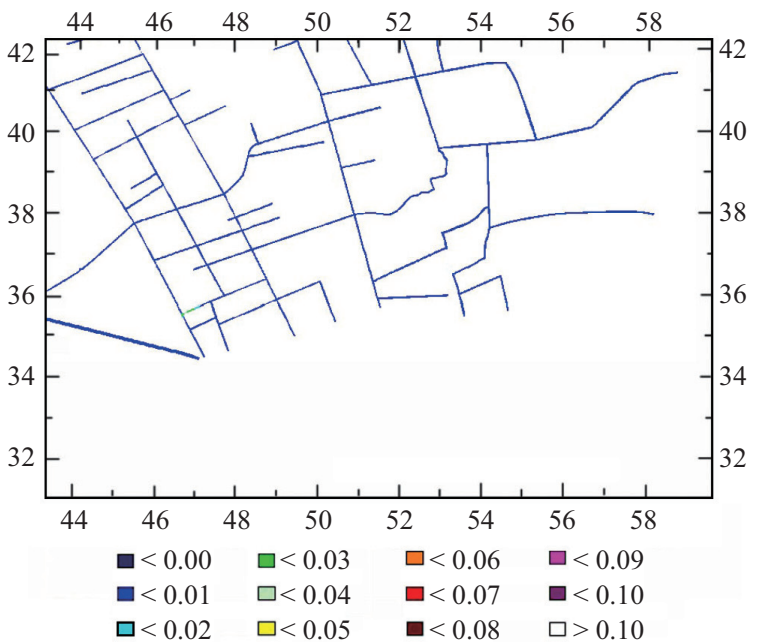

(a) $30 \mathrm{~min}$

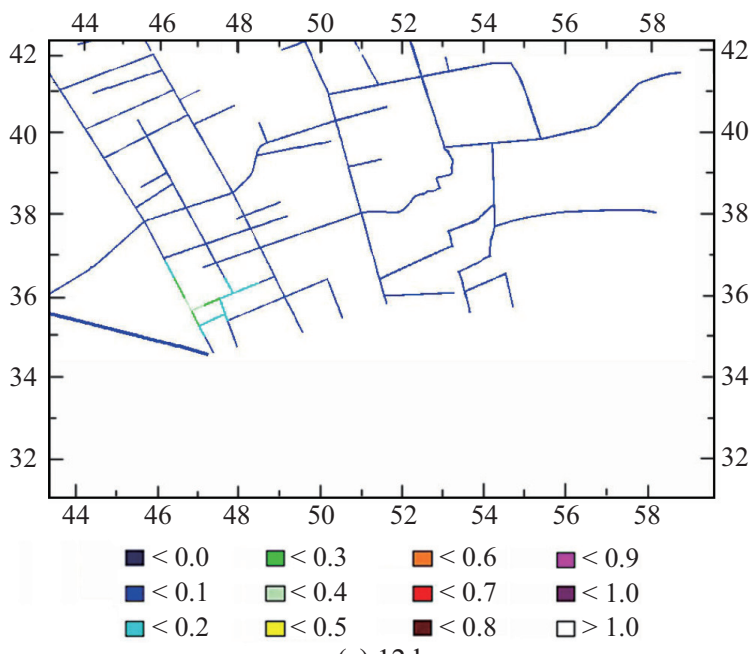

(c) $12 \mathrm{~h}$

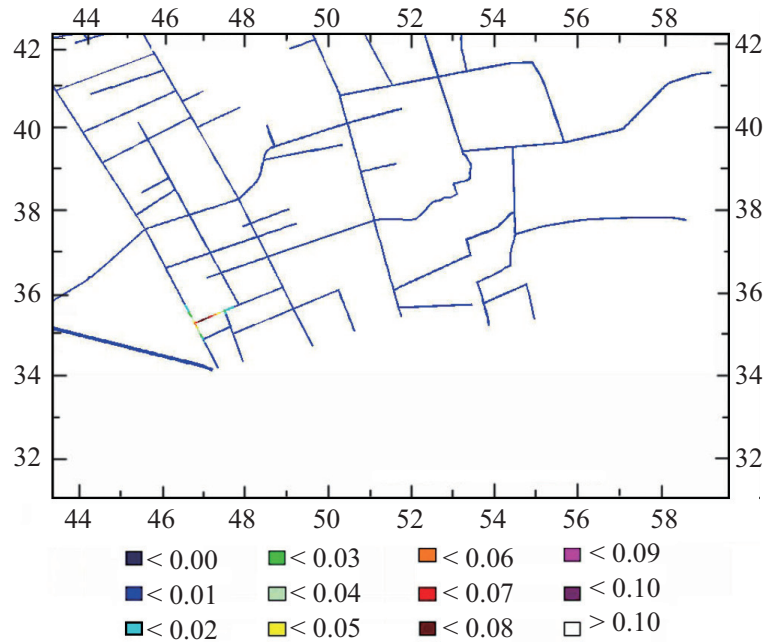

(b) $1 \mathrm{~h}$

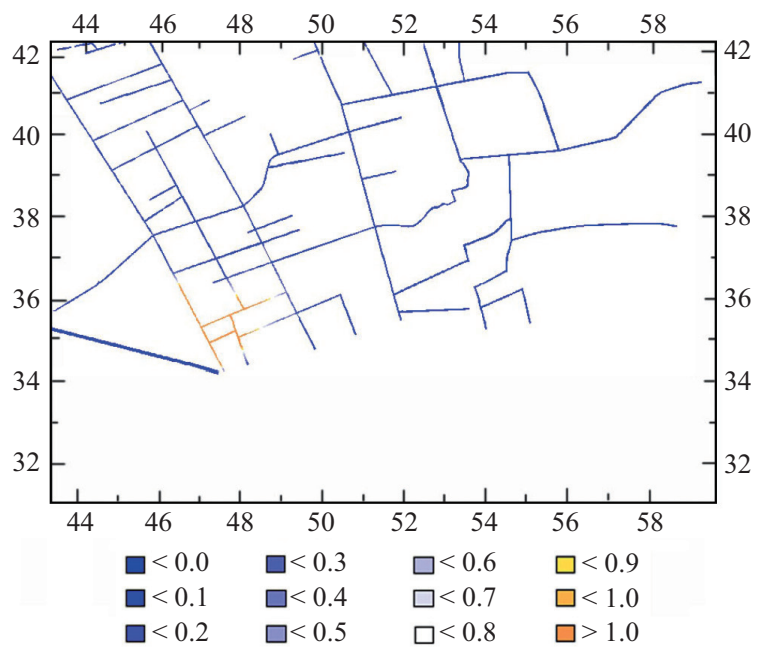

(d) $24 \mathrm{~h}$

Fig. 12. Fate and transport of particulate HCB in the rivers of study domain.

\section{ACKNOWLEDGMENTS}

We would like to thank Ministry of Science and Technology of the P.R.C for the funding of this research project (No.2007AA06A401). We also would like to acknowledge the finance supported by the state's Major Science and Technology Program for Water Pollution Control and Treatment (No.2009ZX07316-005), and the foundation of State Key Laboratory of Pollution Control and Resource Reuse (Tongji University) (No.PCRRY11009).

\section{REFERENCES}

1. Aamo, O. M., Reed, M., and Downing, K., "Oil spill contingency and response (OSCAR) model system: sensitivity studies," International Oil Spill Conference, Ft. Lauderdale, FL, pp. 429-438 (1997).

2. Chao, X. B., Shankar, N. J., and Wang, S. S. Y., "Development and application of oil spill model for Singapore coastal waters," Journal of Hydraulic Engineering, Vol. 129, No. 7, pp. 495-503 (2003).

3. Cheng, N. S., Law, W. K., and Findikakis, A. N., "Oil transport in surf zone," Journal of Hydraulic Engineering, Vol. 126, No. 11, pp. 803-809 (2000).
4. Delft Hydraulics, "Delft3D-WAQ, Simulation of mid-field water quality and oil spills, using particle tracking," Netherland, pp. 100-101 (2007).

5. Jin, W. and Wang, D. Z., "Direct settling velocity direction of sediment using PIV," Journal of Hydrodynamics (Ser. A), Vol. 20, No. 1, pp. 19-23 (2005). (in Chinese)

6. Kobayashi, T. and Yapa, P. D., "Modeling oil deposition on shorelines and re-entrainment," Proceedings of International Conference on Hydraulic and Water Resources Engineering, ASCE, New York, pp. 653-657 (1995).

7. Leech, M., Walker, M., Wiltshire, M., and Tyler, A., "OSIS: A Windows oil spill information system," Proceeding of the 16th Arctic and Marine Oil Spill Program, Technical Seminar, Alberta, Canada, pp. 549-572 (1993).

8. Lick, W., Sediment and Contaminant Transport in Surface Waters, CRC Press, p. 301 (2009).

9. Lunel, T., Swannella, R., Rusina, J., Wood, P., Bailey, N., Halliwell, C., Davies, L., Sommerville, M., Dobie, A., Mitchell, D., McDonagh, M., and Lee, K., "Monitoring the effectiveness of response operations during the Sea Empress incident: a key component of the successful counterpollution response," Spill Science \& Technology Bulletin, Vol. 2, No. 3, pp. 99-112 (1995).

10. Reed, M., Aamo, O. M., and Daling, P. S., "Quantitative analysis of alternate oil spill response strategies using OSCAR," Spill Science and Technology, Vol. 2, No. 1, pp. 67-74 (1995).

11. Reed, M., Ekrol, N., Rye, H., and Turner, L., "Oil Spill Contingency and 
Response (OSCAR) Analysis in Support of Environmental Impact Assessment Offshore Namibia," Spill Science \& Technology Bulletin, Vol. 5, No. 1, pp. 29-38 (1999).

12. Reed, M., Johansen, Ø., Brandvik, P. J., Daling, P., Lewis, A., Fiocco, R., Machay, D., and Prentki, R., "Oil spill modeling towards the close of the 20th century: overview of the state of the art," Spill Science \& Technology Bulletin, Vol. 5, No. 1, pp. 3-16 (1999).

13. Spaulding, M. L., Howlett, E., Anderson, E. L., and Jayko, K., "OILMAP. A global approach to spill modeling," Proceedings of 15th Arctic Marine Oil Spill Program Technical Seminar, Edmonton, Canada, pp. 15-21 (1992).

14. Spaulding, M. L., Kolluru, V. S., and Anderson, E., "Application of threedimensional oil spill model (WOSM/OILMAP) to hindcast the Braer spill,” Spill Science \& Technology Bulletin, Vol. 1, No. 1, pp. 23-35 (1994).

15. Sun, J., Gao, X. H., Yu, J. Q., and Huang, L. W., "Spilled oil information management system for Zhousan Harbour China based on OILMAP," Journal of Wuhan University of Technology (Transportation Science and
Engineering), Vol. 26, No. 5, pp. 700-702 (2002). (in Chinese)

16. Thibodeaux, L. J., Valsaraj, K. T., John, V. T., Papadopoulos, K. D., Pratt, L. R., and Pesika, N. S., "Marine oil fate: Knowledge gaps, basic research, and development needs; a perspective based on the deepwater horizon spill," Environmental Engineering Science, Vol. 28, No. 2, pp. 87-93 (2011).

17. Wang, D. Z., Fang, J. Y., and Zhong, B. C., "Environmental effect of river sediments in coastal regions," CSHydro 2009, National Taiwan Ocean University, Taiwan (2009). (in Chinese)

18. Wu, Z. H. and Yin, H. L., "The oil-droplet concentration distribution and its pollution zone numerical computation on condition of limited length oil slick on water surface," Environmental Hydraulics and Eco-Hydraulics (Theme B), 21st Century - The New Era for Hydraulic Research and its Applications, pp. 152-157 (2001)

19. Xu, Z. X. and Yan, Z. C., "Methodology of longitudinal dispersion coefficient in river flows," Shanghai Environmental Sciences, Vol. 22 (supplement), pp. 135-137 (2003). (in Chinese) 